\title{
THE USE OF 3D SCANNING AND PHOTOGRAMMETRY TECHNIQUES IN THE CASE STUDY OF THE ROMAN THEATRE OF NIKOPOLIS. SURVEYING, VIRTUAL RECONSTRUCTION AND RESTORATION STUDY.
}

\author{
T. Bilis ${ }^{\text {a }}$, T. Kouimtzoglou ${ }^{\text {b }}$, M. Magnisali ${ }^{c}$, P. Tokmakidis ${ }^{d}$ \\ a Architect, Phd Candidate NTUA, 4 P. Ioakim st., 17121, Athens, Greece - themisbilis@yahoo.gr \\ ${ }^{\mathrm{b}}$ Architect, Phd Candidate NTUA, 22A Olympoy st., 15235, Athens, Greece - kouim@yahoo.com \\ ${ }^{c}$ Architect, Phd Candidate NTUA, 21 Venizelou st., 17123, Athens, Greece - magnisali@yahoo.gr \\ ${ }^{\mathrm{d}}$ Rural and Surveying Engineer, PhD Candidate AUTh, 32 Democritu st., 55132, Kalamaria, Greece - ptokmaki@ gmail.com
}

\section{Commission II}

KEY WORDS: Theatre, Roman, Nikopolis, 3D scanning, Photogrammetry, Monument, Restoration

\begin{abstract}
:
The aim of this paper is to present the specific methods by which 3D scanning and photogrammetric techniques were incorporated into the architectural study, the documentation and the graphic restoration study of the monument of the ancient theatre of Nikopolis. Traditional methods of surveying were enhanced by the use of 3D scanning and image-based 3D reconstruction and 3D remodelling and renderings. For this reason, a team of specialists from different scientific fields has been organized. This presented the opportunity to observe every change of the restoration design process, not only by the use of common elevations and ground plans, but also in 3D space. It has been also very liberating to know how the monument will look like in this unique site after the restoration, so as to obtain at the study stage the best intervention decisions possible. Moreover, these modern work tools helped of course to convince the authorities for the accuracy of the restoration actions and finally to make the proposal clear to the public.
\end{abstract}

\section{INTRODUCTION}

The roman theatre of Nikopolis (Zachos et al, 2010; Zachos, 2012; Zachos et al, 2015; Zachos, 2015) is located near the city of Preveza at Epirus and within the broad archaeological site of the roman city of Nikopolis, in a scenery of astonishing beauty. It is one of the greatest monuments of the roman period in Greece. Its construction is a part of Octavian's ambitious constructive program at Nikopolis at the beginning of the1st $\mathrm{c}$ AV.

The theater in the course of time especially in the $2 \mathrm{nd}$ c. AD has been reconstructed fundamentally; it became even more luxurious, with a higher stage building and a gallery on the upper limit of the cavea. After the collapse of the ancient world, the theater has lost its functional purpose but also its symbolic value. Luxurious materials have been removed and almost all limestone seats became lime in order to be used to the ambitious programs of the new Christian city. The theater is larger than the Odeon of Herodes Atticus in Athens and used to have a capacity that could accommodate 8,000 spectators, with luxurious materials and a huge shading-tent system (velarium) for spectators like the one at Colosseum and other famous theatres of the roman world. Unfortunately, this monument encounters several architectural and structural issues. These are the main features of the monument. The ruin is saved to a large extent $(9000 \mathrm{~m} 2)$, with significant structural problems. At the same time the ruin reveals important presentation capabilities. The key point for this presentation and restoration study (Bilis, T., Magnisali, M., 2016) has been the study of the original architectural form of the monument. It is difficult, for the original form of the building to be conceived, due to almost complete loss of marble, architectural cladding and serious loss of large masses of its structure (Figure 1), for example, the endings of the scene building towards the corners, where the scene building meets the exterior wall of the theatre. Possibly, staircases were located at the rear of the scene building by the towers of the backstage-versurae. From the stoas, ornamenting its façade, only foundations are preserved.

The magnificence of this theatre, its general design as also its details, reveals the intentions of a great gift of the Emperor to the city of Nikopolis. The large scale of several parts of the monument is very impressive. Many elements determine precisely the dimension of the height of the ancient construction, something quite rare for a monument of antiquity in Greece.

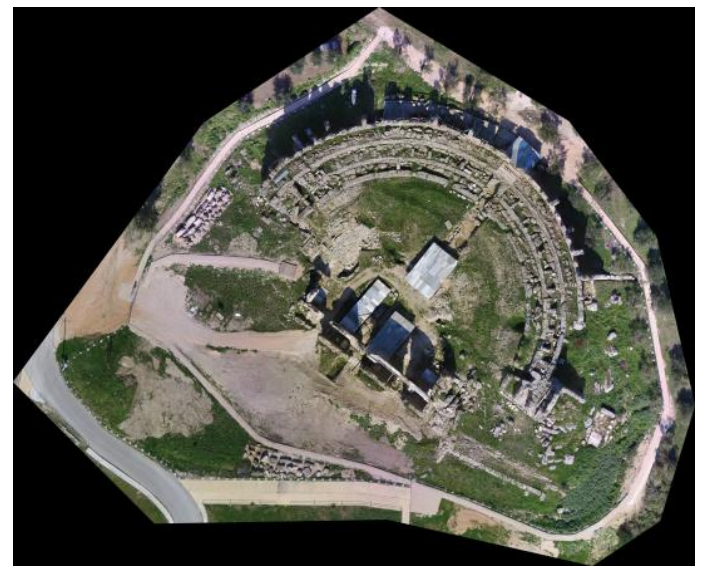

Figure 1. Ancient Nikopolis theatre. Drone orthophotograph.

\footnotetext{
* Corresponding author
} 
The mechanism of destruction, such as creeps and anisotropic foundation behaviors, mainly because of the soil instability and pressure of the slipping ground of the hill and also because of seismic activity, have caused serious damage and deformations in the horizontal and vertical plane, a phenomenon observed to a great extent in the ruin.

\section{RELATED WORK AND SPECIFIC APPROACH}

As roman theatres can be found in many areas of the mediterrenean in the Greco-Roman world, there are examples of architectural documentation and surveying with modern methods and techniques (Haddat et al, 2005; Grussenmeyer et al, 2012); Nocerino et al, 2014; Balletti et al, 2015; Farella et al, 2016; Quattrini et al, 2016). The typical data acquisition procedure is done by terrestrial laser scanning and/or image based reconstruction along with classical surveying methods.

The same methodology has been applied in the project of Nikopolis. Especially, for the scenae, a method that combines photogrammetry and laser scanning has been used, in order to achieve better texture quality and in this way add an additional level of detail. Since Roman constructions consist of smaller structural parts, compared to classical ones, a higher level of texture detail is essential for studying the defects of the construction. Another addition to the usual methodology is the unrolled elevation plan of the koilon. Using the unroll technique, the cylindrical shape of the koilon can be printed on a regular paper plan and once again this enables the team to work in a 2D surface manner and indicate on the plan, defects, cracks, structural elements that need replacement etc.

Restoration is a synthesis based strictly on the body of the monument. The limits of the restoration actions are conducted by the features and the condition of the surviving parts of the monument. It is of great importance the severe approach of the available material and the precise control of the restoration's intentions. The complexity of the aims of this ambitious project (conservation, partial restoration and partial use for cultural activities) had to balance with the image of the ruin. So, the technical choices and the visual results of them thanks to digital applications became an interactive process in real time.

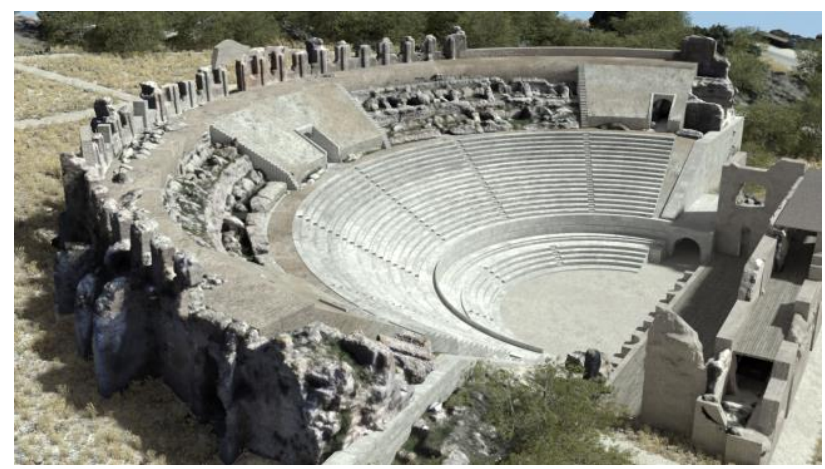

Figure 2. 3D virtual representation of the restoration proposal: General view.

Even from the early stages of the restoration study, a 3D model of the proposal has been used to help understand the best restoration strategy and what the effects will be on the final restored monument and surrounding space. The 3D model of the proposal was continuously evolving and adapting to the changes of the architectural study and was not constructed after its conclusion. It was used not only as a presentation media of the final outcome, but also as a digital tool that facilitated the process. Unlike other approaches (Farella et al, 2016; Quattrini et al, 2016) where separate surveying or proposal models can be observed, the final 3D model of Nikopolis theatre is a hybrid model consisted of both partially the original 3D surveying model and the $3 \mathrm{D}$ geometry of the proposed restoration.

\section{ARCHITECTURAL DOCUMENTATION}

We believe that the accurate documentation of the deformations or deflections of this construction and the study of the mechanism that destroyed the efficiency of this strongly reinforced construction provide precious information for the original architectural design. In that way, the correct presentation of the monument to the public and the scientific society will become possible. Considering restoration study and careful restoration itself, as the best way to evolve the study of a monument, we think that this study will initiate future research. For the maximum accuracy of documentation traditional methods of surveying were enhanced by the use of 3D scanning and image-based 3D reconstruction and 3D remodeling and renderings. A team of specialists from different scientific fields has been organized. This offered the opportunity to observe every change of the restoration design process, not only by the use of common elevations and ground plans (Figure 3, Figure 4, Figure 6, Figure 7), but also in 3D space. It has been also very liberating to know how the monument will look like in this unique site after the restoration, so as to obtain at the study stage the best intervention decisions possible (Figure 2). Moreover, these modern work tools helped of course to convince the authorities for the accuracy of the restoration actions and finally to make the proposal clear to the public.

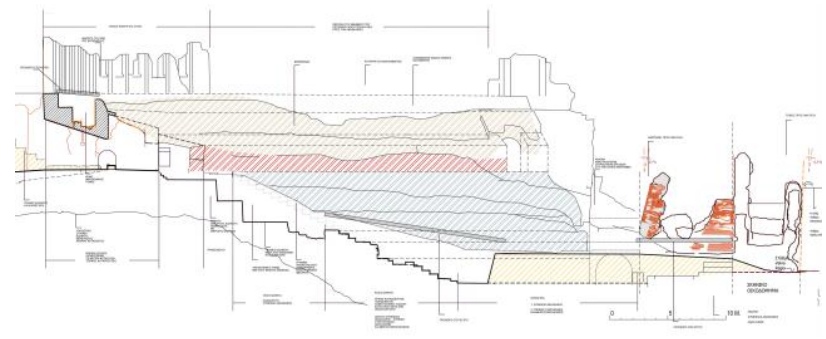

Figure 3. Theatre of Nikopolis. Section, current state of the theatre.

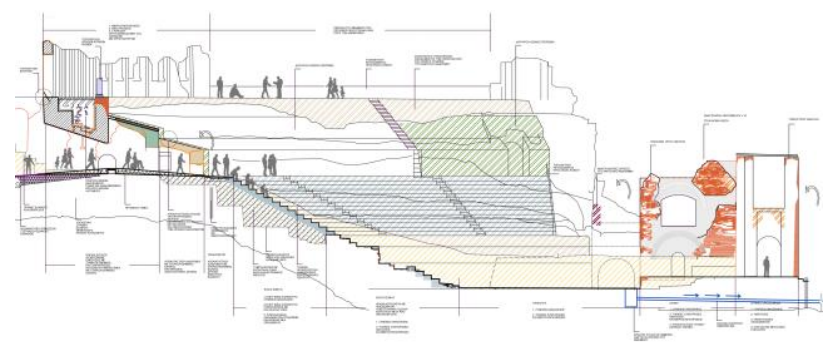

Figure 4. Theatre of Nikopolis. Section, restoration proposal.

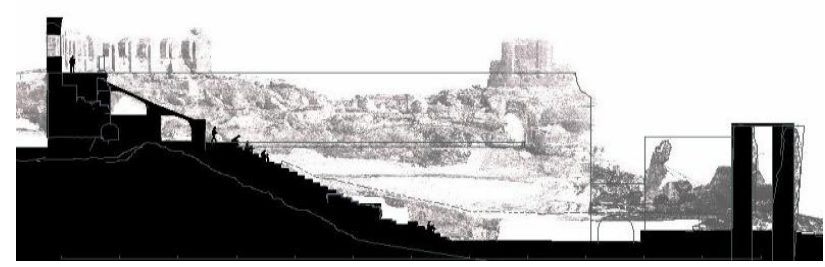

Figure 5. Restoration proposal: Section of the theatre. 
Special architectural measurements with traditional methods of documentation have been conducted, so as to discern the dimensions and special characteristics of each of the parts that compose the theatre. In the meantime, documentation of walls with unusual height, cracks and deflections from verticalness was a challenge for the surveying, the interpretation of deterioration factors and the analysis of the phenomenon of collapse. One of the tasks was to evaluate all the collected data so as to realize the possibilities for the restoration and presentation of the theatre. The detailed measurements, provided by the 3D scanning procedure, were the basis for other parallel studies such as study of material conservation and others. The aim of this study is, at the end, the opportunity to present to the public the "real" experience of the restored monument.

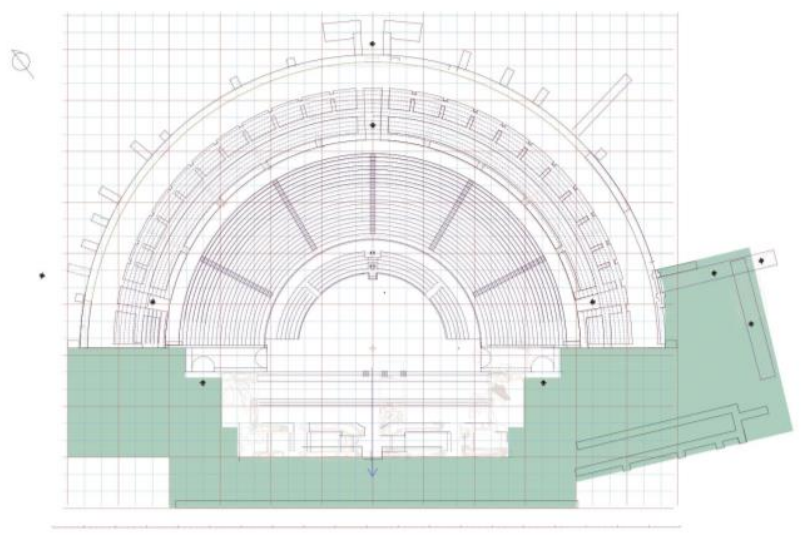

Figure 6. Theatre plan.

The ancient theatre, in the extent it has been revealed, follows strictly the metrical orders of its time. As it becomes clear every special feature of the construction is designed using the roman foot and its multiples. For example, the dimensions of the walls, the openings, the vomitoria and other architectural elements but also structural elements such as bricks and vaults. As for the larger parts of the theatre, their dimensions follow an emvatis. We have also detected that there was also a larger emvatis for the design of the general parts of the constructions. Simple proportions and symmetry were used in the architectural synthesis. For example, the inner radius of the ima cavea is needed twice for the external radius of ima cavea with the praecinctio and one more time for the summa cavea with the exterior wall and its supports.

\section{DATA ACQUISITION}

In order to capture the initial state of the monument, a 3D laser scanner and photogrammetric techniques were combined. The first task was to complete a map of the monument with the surrounding area in order to plan the rest of the survey. For this purpose, the fastest method would be aerial photogrammetry using a UAV.

Sixteen artificial targets have been placed in the greater area of the monument and inside it, all of them were measured with a GNSS receiver using Network RTK technique, with an averaging of 30 measurements per target point. Then, the UAV flight was planned on a map and finally the UAV autonomously followed the flight plans and took the aerial images. Three flights were needed to capture the whole scene from about $30 \mathrm{~m}$ above the monument. The UAV geotagged all the images, using the built-in GNSS receiver, used for easier image registration on post-processing. The images were then processed and the artificial-targets have been indicated on the images semiautomatically. The result of this workflow was the creation of a digital 3D terrain model of the surrounding area and a true orthophoto.

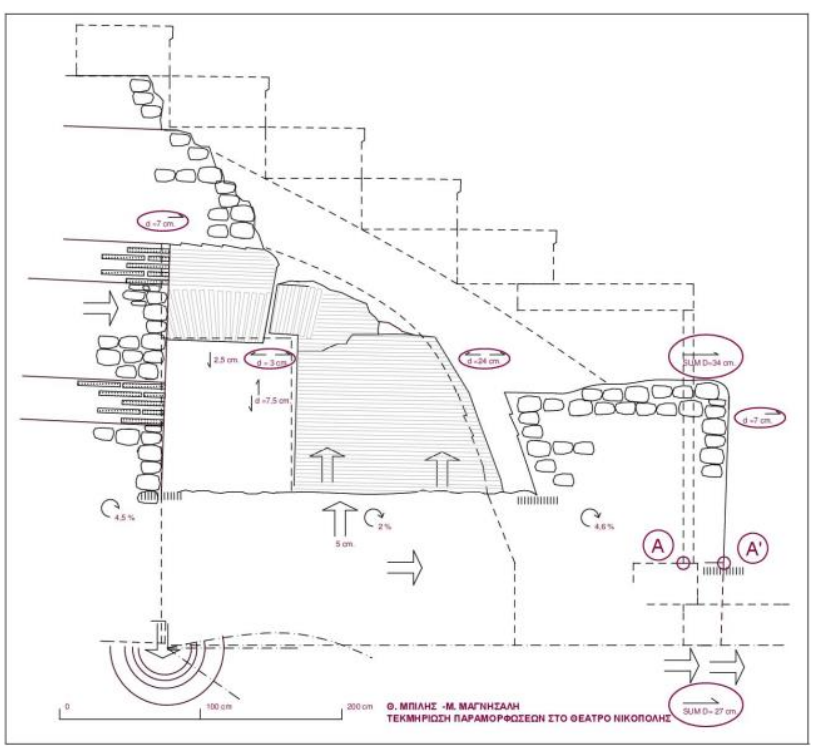

Figure 7. Section. Detail of deformation.

The orthophoto has been printed and used for the planning of the laser scanner survey. 65 scans were made inside the scenae and koilon and another 69 scans for the perimeter of the koilon and the newest excavation sections inside it. Spherical targets and printed (A4 sized) checkerboards have been used, for the registration of the laser scans. Some of them were common with the ones used for the UAV capture. Finally in order to achieve greater color detail at the final 3D point-cloud of the scenae, all the facades have been photographed using a Digital SLR camera. So in scenae, the geometric information derived from the laser scanner, but the texture was aqquired from the DSLR images.

The results of the 3D survey were, a high detail 3D pointcloud of the whole monument (Figure 8, Figure 9), a floor plan, elevations and sections at specific areas and an unrolled elevation plan of the perimeter of the koilon (Figure 11). The last one is particularly interesting. In order to produce this unrolled plan, specific points on the perimeter of the koilon have been chosen. From these points, a cylinder's center has been estimated using least squares estimation. This ideal cylinder has been extended just $1 \mathrm{~m}$ outside of the perimeter and the cylindrical wall has been projected onto it. Finally, the ideal cylinder, with the projected perimeter of the koilon on it, has been unrolled in order to produce the final elevation plan. It is understood that this plan has several distortions on the $\mathrm{X}$ axis, but it is the only way to visualize the cylindrical surface on paper and observe the defections, cracks etc.

\section{3D VIRTUAL RECONSTRUCTION OF THE RESTORATION PROPOSAL}

The 3D mesh and the accompanying textures that were produced by the aforementioned procedures, were also used to create a photorealistic and scaled digital scene of the project, depicting the current state of the monument (before the excavations and the restoration proposal) (Figure 12). 
The use of the model in the 3D space gave the possibility to examine the existing condition of the theatre from every necessary angle and focus in specific areas of interest. The removal of the texture layer provided the opportunity to examine a clearer model by showing only geometric data and focusing on the immediate relation of the monument and the surrounding landscape (Figure 10).

In order to achieve a high level of realism, certain technical considerations had to be taken into account, such as the global illumination and the sun/shadow position in order to match the light/shadow information of the recorded texture data

Figure 12). The $3 \mathrm{~d}$ mesh was also used to automatically extract accurate sections (top surface level only) of the model: the theatre and the surrounding grounds and landscape (Figure 13).

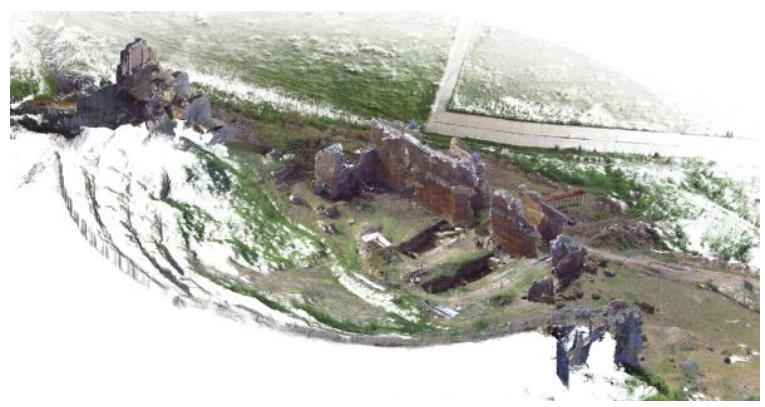

Figure 8. Point cloud of the theatre.

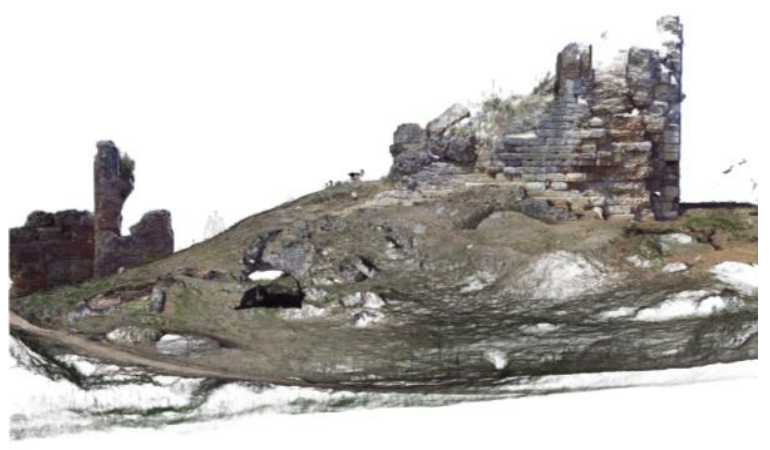

Figure 9. Point cloud detail.

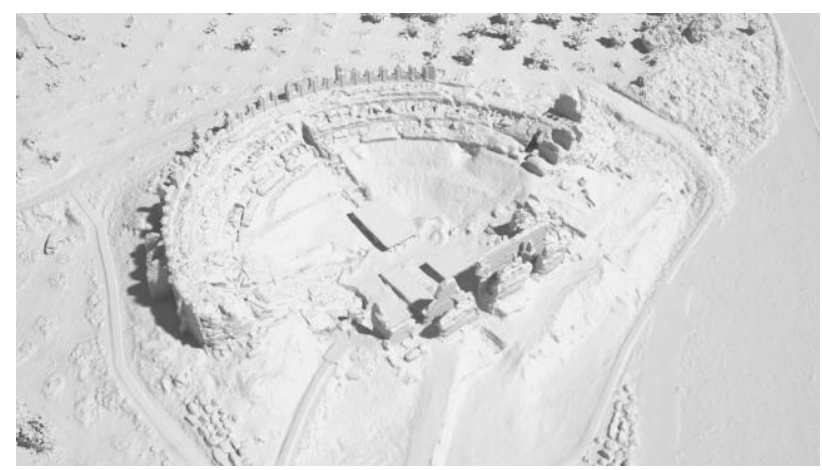

Figure 10. Untextured model of the current state of the theatre.

Finally, the 3D textured mesh of the theatre, was used as the base for a new 3D digital model that is presenting the restoration and excavation proposal (Figure 2, Figure 15).

Certain areas of the original model were removed and were replaced by the proposed restored geometry, according to the

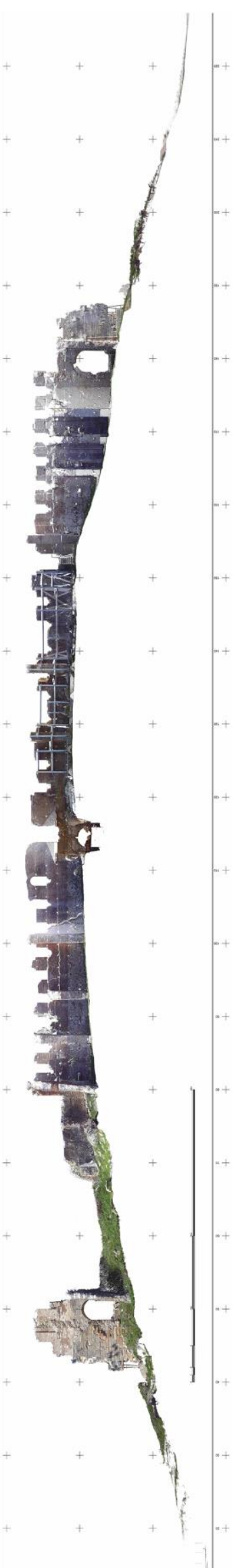

Figure 11. Unrolled elevation plan of the perimeter of the koilon. 


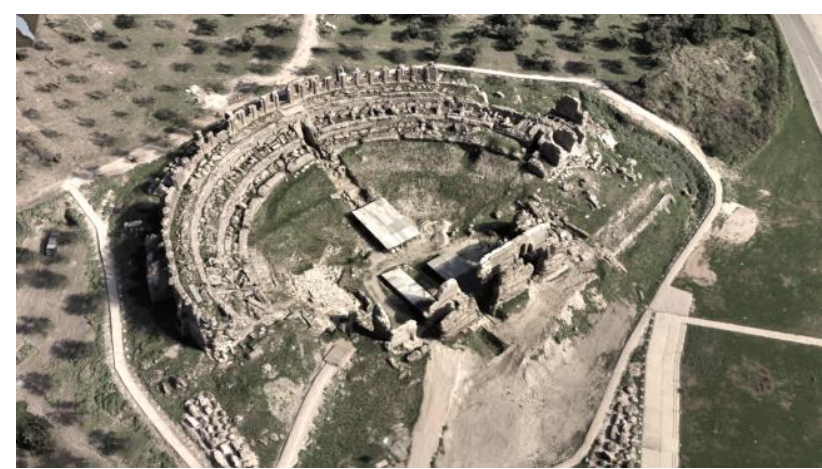

Figure $12.3 \mathrm{D}$ rendering of the current state of the theatre.

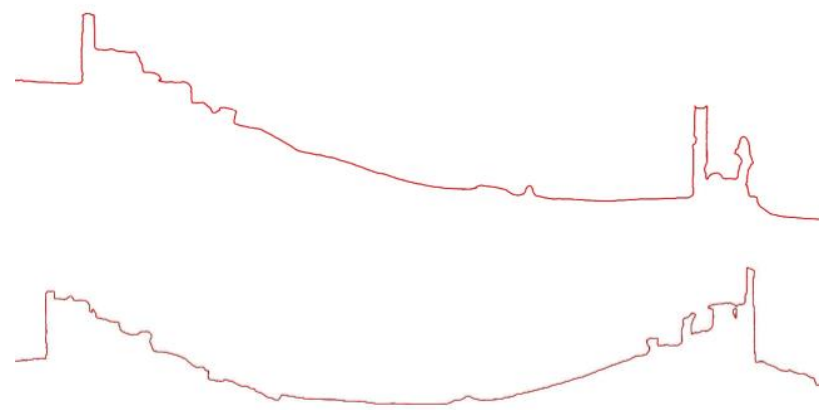

Figure 13. 3D model automatically generated surface sections.

anastylosis plans of the monument. The geometry of the koilon has been remodelled, according to the architectural plans, and was incoporated into the modified 3D model (Figure 14). The scenae was also digitally rebuilt and was correlated to the original geometry. The surrounding ground mesh was removed and specific areas were also remodelled in order to lower the level of the surroundings and the orchestra ground level to the appropriate one, according to the anastylosis proposal and the excavation levels.

This $3 \mathrm{~d}$ digital virtual restoration process can present as a whole the different states of the monument, the current and the proposed one. All the interventions can be clearly shown in the form of diagrams and $3 \mathrm{~d}$ representations. The laser scanning and photogrammetry information is used as foundation data that can be an invaluable tool for the assessment of the existing condition and the control of the intervention proposal by the use of $3 \mathrm{D}$ geometry in virtual space.

\section{CONCLUSIONS}

In this paper, a method of parallel use of different techniques from different scientific fields is presented, having as aim the restoration study of an important building of the Antiquity. It should be stressed that the produced material (images, drawings) from the 3D cloud data, improves the process of the architectural study by decreasing the time needed for documentation and fulfills the spatial approach of every proposed restoration action. The detailed documentation reveals the history of the building, the principles of the original architectural form of the building and illuminates the interpretation of the causes of decay. The production of diverse visual material, with the use of specific architectural and surveying software, in the frame of using 3D models as the first step of the eventual restoration, improves the communication between the participants of the study and the society.

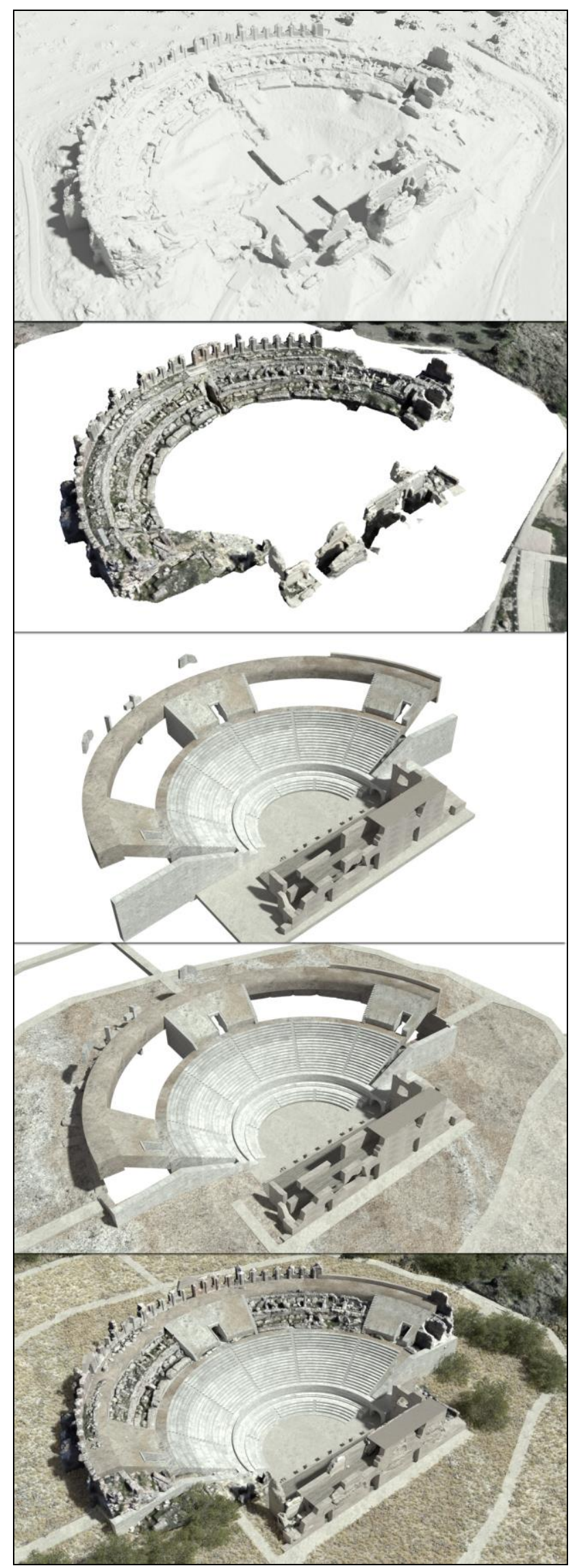

Figure 14. Stages of the procedure for the combination of the original 3D model and the restoration proposal 3D model. 


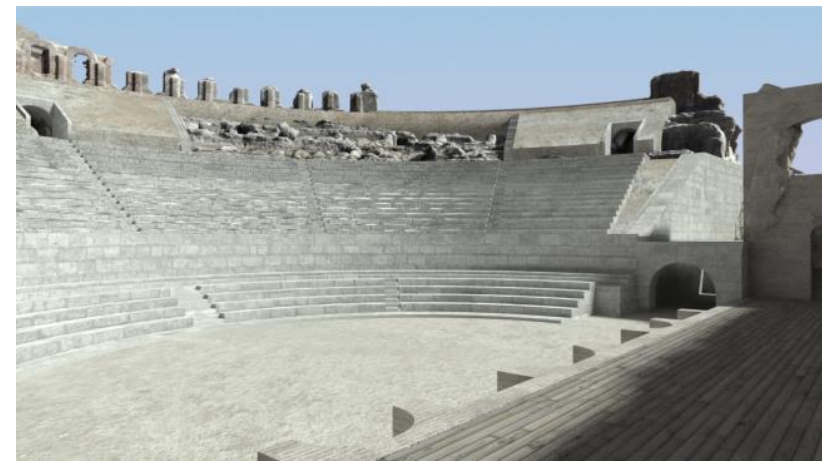

Figure 15. 3D Virtual representation of the restoration proposal: Koilon and scenae.

\section{ACKNOWLEDGEMENTS}

We owe many thanks to the Ministry of Culture and especially D. Svolopoulos, director of the Directorate of Ancient Monuments, E. Kountouri, director of the Directorate of Prehistoric and Classical Antiquities, A. Aggeli, director of the Ephorate of Prehistoric and Classical Antiquities of Preveza and E. Chalkia, president of the scientific committee of Nikopolis and especially K. Zachos, excavator of the theatre, Diazoma Association for trusting us this study and Stavros Niarchos Foundation who supported the restoration study.

\section{REFERENCES}

Balleti, C., Guerra, F., Scocca, V., Gottardi, C., 3D integrated methodologies for the documentation and the virtual reconstruction of an archaeological site, 2015. The International Archives of the Photogrammetry, Remote Sensing and Spatial Information Sciences, Volume XL-5/W4, 3D Virtual Reconstruction and Visualization of Complex Architectures, 25-27 February 2015, Avila, Spain.

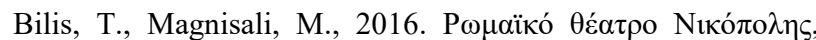

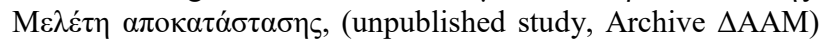
Athens.

Devrim, A., Gruen, A. 2007. Generalized least squares multiple 3D surface matching. Int. Arch. Photogramm. Rem. Sens. Spatial Inf. Sci 36.3/W52 (2007): 1-7.

Farella, E., Menna, F., Nocerino, E., Morabito, D., Remondino, F., Campi, M., 2016. Knowledge and valorization of historical sites through 3D documentation and modellig. The International Archives of the Photogrammetry, Remote Sensing and Spatial Information Sciences, Volume XLI-B5, 2016, XXIII ISPRS Congress, 12-19 July 2016, Prague, Czech Republic

Grussenmeyer, P., Alby, E., Landes, T., Koehl, M., Guillemin, S., Hullo J.-F., Assali, P., Smigiel, E., 2012. Recording approach of heritage sites based on merging oint clouds from high resolution photogrammetry and terrestrial laser scanning, International Archives of the Photogrammetry, Remote Sensing and Spatial Information Sciences, Volume XXXIX-B5, 2012, XXII ISPRS Congress, 25 August - 01 September 2012, Melbourne, Australia.
Haddad, N., Akasheh, T., 2005. Documentation of archaeological sites and monuments: Ancient theatres in Jerash, CIPA 2005 XX International Symposium, Torino, Italy

Nocerino, E., Menna, F., Remondino, F., 2014. Accuracy of typical photogrammetric networks in cultural heritage 3D modeling projects, The International Archives of the Photogrammetry, Remote Sensing and Spatial Information Sciences, Volume XL-5, 2014, ISPRS Technical Commission V Symposium, 23 - 25 June 2014, Riva del Garda, Italy

Quattrini, R., Pierdicca, R., Frontoni, E., Barcaglioni, R., 2016. Virtual reconstruction of lost architectures: From the TLS survey to Ar visualization, The International Archives of the Photogrammetry, Remote Sensing and Spatial Information Sciences, Volume XLI-B5, 2016, XXIII ISPRS Congress, 12 19 July 2016, Prague, Czech Republic.

Remondino, F., Gruen, A., Von Schwerin, J., Eisenbeiss, H., Rizzi, A., Sauerbier, M., Richards-Rissetto, H., 2009. Multisensors 3D documentation of the Maya site of Copan. ISPRS Archives Vol. XXXVIII-3/W8, XXII CIPA Symposium, 2009, Kyoto, Japan.

Rizzi, A., Baratti, G., Jiménez, B. , Girardi, S., Remondino, F., 2011. 3D recording for 2D delivering - The employment of 3D models for studies and analyses, International Archives of the Photogrammetry, Remote Sensing and Spatial Information Sciences, Volume XXXVIII-5/W16, 2011 ISPRS Trento 2011 Workshop, 2-4 March 2011, Trento, Italy

Romeo, E., Rudiero, R., 2013. Ruins and urban context: Analysis towards conservation and enhancement, International Archives of the Photogrammetry, Remote Sensing and Spatial Information Sciences, Volume XL-5/W2, XXIV International CIPA Symposium, 2 - 6 September 2013, Strasbourg, France.

Skarlatos, D., Theodoridou, S., Glabenas, D., 2004. Archaeological surveys in Greece using radiocontrolled helicopter. In: Proceedings of the FIG Working Week, 2004, International Athenaeum Athens, Athens, Greece.

Theodoridou, S., Tokmakidis, K., Skarlatos, D., 2000. Use of radio-controlled model helicopters in archaeology surveying and in building construction industry. ISPRS Archives Vol. XXXIII-B5, XIX ISPRS Congress, 2000, Amsterdam, The Netherlands.

Tokmakidis, K., Skarlatos, D., 2000. Mapping excavations and archaeological sites using close range photos. In: Proceedings of the ISPRS Commission V Symposium, WG V/4, 2000, Corfu, Greece.

Tokmakidis, K., 2009. Surveying the Eupalinian Aqueduct in Samos Island, proc. of 22nd International CIPA Symposium "Digital Documentation, Interpretation and Presentation of Cultural Heritage", 2009, Kyoto, Japan, CD-ROM, 5 pages.

Tokmakidis, P., Spatalas, S., Tokmakidis, K., Tsioukas, V., 2014. Laser scanning in the service of the visually impaired, proc. of 1 st International Geomatics Applications "Geomapplica" Conference, 2014, Skiathos Island, Greece, USB-Drive, 6 pages.

Vozikis, G., 2007. Using hybrid surveying techniques for documenting the largest ancient theater in Greece, proc. of XXI 
International CIPA Symposium, 2007, Athens, Greece, pp. 739742 .

Zachos, K., Pavlidis, E., Tranoulidis, A., 2015. The theatre of Nicopolis, Athens.

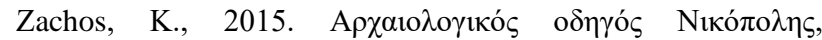

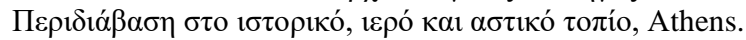

Zachos, K., Pavlidis E., 2010. Die frühen Bauten von Nikopolis. Bemerkungen zu den bauphasen und techniken der Kaiserzeit, in Asskamp R. \& Tobias E. (Hrsg.) IMPERIUMVarus und seine Zeit. Beiträge zum internationalen Kolloquium des LWL- Römermuseums am 28. Und 29. April in Münster, Aschendorff Verlag, p.135-152.

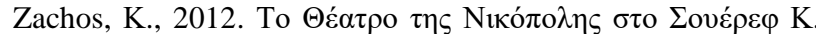

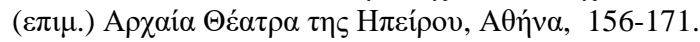

http://www.diazoma.gr/gr/Page_60-36.asp. http://www.diazoma.gr/en/Page_60-36.asp. http://odysseus.culture.gr/h/2/eh251.jsp?obj_id=6021 http://www.lgepka.gr/theatronicopoli.html http://www.blod.gr/lectures/Pages/viewlecture.aspx?LectureID= 2769

\section{APPENDIX}

Glossary :

Emvatis - special module multiple of roman foot ima cavea - lower part of the seating area summa cavea - upper part of the seating area praecinctio - corridor between ima and summa cavea velarium - shading-tent system

koilon - seating area 